\title{
Issues in Utility Measurement
}

\author{
Michael H. Birnbaum \\ Irvine Research Unit in Mathematical Behavioral Science \\ California State University, Fullerton
}

\begin{abstract}
Descriptive theories of decision making are constrained by the need to explain the following behavioral phenomena: risk aversion, gambling, purchases of insurance, investment, the paradoxes of Allais and Ellsberg, intransitivity of preference, irregularities of choice, preference reversals, risk judgments, violations of branch independence, the difference between buying and selling prices, violations of monotonicity, and the relationships between risky and riskless situations. The papers in this special issue on utility theory address these empirical phenomena and explore theories proposed to explain them. 1992 Academic Press, Inc.
\end{abstract}

The study of human decision making has become a study of how people depart from theories that stipulate how one ought to made decisions. A rational decision maker should choose the course of action that is anticipated to lead to the best results, but there is some room for disagreement about the definitions of "anticipated" and "best." In recent years, psychologists have concluded that people consistently violate principles of decision making that have been held to be "rational." This special issue presents a collection of papers that test implications of psychological theories proposed to explain the following behavioral phenomena.

\section{"RISK AVERSION"}

Most people prefer the expected value of a gamble to the gamble itself. Indeed, most would prefer $\$ 40$ for certain, rather than take a 50-50 gamble to receive $\$ 100$ or $\$ 1$, even though the gamble has a higher expected value $(\$ 50.50)$. The fact that people have definite preferences among gambles of constant expected value led to the development of the theory of utility. If utility is a logarithmic function of money, as proposed by Bernoulli, then the utility of $\$ 10$ should match the expected utility of the $50-50$ gamble between $\$ 1$ and $\$ 100$. A negatively accelerated utility function would also explain why people will pay more than the expected loss to buy insurance.

This work was supported by NSF Grant SES 8921880 and by a Senior Faculty Fellowship from California State University, Fullerton. Thanks are due Steven McCormick for assistance in preparation of the manuscript. Address correspondence and reprint requests to the author at Department of Psychology, CSUF, Fullerton, CA 92634. 
Expected utility theory was formalized by von Neumann and Morgenstern (1947) and extended to events that did not have specified, objective probabilities by Savage (1954), who developed subjective expected utility theory. Evaluations of these theories and extensions are presented in Edwards (1954), Fishburn (1983), Keeney and Raiffa (1976), Krantz, Luce, Suppes, and Tversky (1971), Payne (1973), Raiffa (1968), Schoemaker (1982), Slovic, Lichtenstein, and Fischhoff (1988), and von Winterfeldt and Edwards (1986).

Equation (1) specifies a class of nonconfigural utility theories:

$$
\mathbf{U}=\sum s\left(p_{i}\right) u\left(x_{i}\right),
$$

where $\mathrm{U}$ represents the overall utility of a gamble to receive outcome $x_{i}$ with probability $p_{i} ; s\left(p_{i}\right)$ and $u\left(x_{i}\right)$ are subjective weights of probability and utility of outcomes; and the summation is over all mutually exclusive and exhaustive outcomes $\left(\Sigma p_{i}=1\right)$. When $s(p)=p$, Eq. (1) reduces to expected utility theory; when $\mathrm{u}(\mathrm{x})=x$ and $s(p)=p$, it reduces to expected value theory. Equation (1) is called "nonconfigural" because the functions, $s(p)$ and $u(x)$, are independent of the other outcomes and probabilities in each gamble. Despite the ability of Eq. (1) to explain risk aversion and the flexibility offered by two unspecified functions, experimental evidence is accumulating against the theory that one can predict actual decisions, bids, or ratings from $\mathrm{Eq}$. (1).

\section{RISKY VS RISKLESS UTILITY}

Expected utility theory leads to scales of the utility of money that disagree with estimates of utility based on riskless judgments (Bell \& Raiffa, 1988; Hershey, Kunreuther, \& Schoemaker, 1982; von Winterfeldt \& Edwards, 1986; Tversky, 1967; Stevens, 1975; Stevenson, 1986). For example, the same subject might judge a $50-50$ gamble to receive either $\$ 0$ or $\$ 96$ to be worth $\$ 24$, yet judge the "difference" in utility between $\$ 96$ and $\$ 24$ to exceed the "difference" in utility between $\$ 24$ and $\$ 0$.

Some investigators assumed that expected utility theory is true and postulated that there are two scales, "utility" and "value," for risky and riskless situations, respectively (e.g., Bell \& Raiffa, 1988). Others proposed that utility should be an invariant construct and argued against expected utility theory. For example, Birnbaum and Sutton (1992) found that a rank-dependent, configural-weight model yields a scale of money that is compatible with buying and selling prices and also with scales estimated from judgments of "ratios" and "differences" in the riskless utility of monetary amounts. Because the scales derived from Eq. (1) were different for buying and selling prices and also differed from scales that fit riskless judgments, Birnbaum and Sutton argued against noncon- 
figural theories in favor of a theory that can explain all of the data with a single utility function.

Shanteau and Troutman (1992) address a problem in riskless utility that has long interested economists and psychologists, the utility function for numbers of a good. Many economic texts begin with an imagined case of two people, for example, shipwrecked sailors on an island. One of them has one commodity, say cans of drink, and the other has another, say bags of food. Each person is willing to trade some of what he has to obtain some of the other's goods. The conclusion that both people want to exchange is a consequence of negatively accelerated scales of utility: The first unit of the new good is worth more than the last unit of the plentiful good. Thurstone (1931) tested a particular theory of "riskless utility." Riskless utility, however, became controversial among economists once it was realized that interesting results could be derived without assuming specific theories of utility indifference (see e.g., Ferguson, 1966, pp. 1125).

Shanteau and Troutman (1992) review some of this controversy and test the theory that the shape of diminishing marginal return is the same for all goods. Their test makes use of Shanteau's (1974) method for assessing the multiplicative model. Because the multiplicative model defines a meaningful scale, if the model is successful it becomes an empirical question whether riskless utility, so defined, is the same construct as utility derived from risky choices.

Stevenson (1992) explores whether different scales are needed for risky and riskless investments that play out over time. Most people would prefer a positive outcome immediately rather than a larger one at a later time; only when interest rates are high enough will people invest. One aspect of long-term investment (besides having one's money tied up) is that risks of loss accumulate over time (Stevenson, 1986). Stevenson (1992) investigates how the discounting effects of time depend on risk and on context. She develops a set of equations to show how time and probability trade off.

\section{GAMBLING AMONG THE "RISK AVERSE" AND ALLAIS' PARADOX}

Multiplication of the probabilities by a constant can reverse the rank order of preference between gambles (Allais, 1979; Kahneman \& Tversky, 1979; Schoemaker, 1982), contrary to expected utility theory. For example, many people prefer $\$ 3000$ for sure to a gamble with a .8 chance to win $\$ 4000$; however, (multiplying both chances by .25 ), the same people prefer a .2 chance at $\$ 4000$ over a .25 chance at $\$ 3000$.

People who ordinarily seem "risk averse" sometimes appear "risk seeking." For example, people who would not pay expected value to play 
a 50-50 gamble will pay more than expected value to buy a state lottery ticket that offers a tiny probability of a large payoff.

Such paradoxical changes from what was interpreted as "risk aversion" to "risk seeking" could be explained by a version of subjective expected utility theory, in which the subjective weights of probabilities don't match objective probabilities and need not sum to one (Edwards, 1954; Kahneman \& Tversky, 1979). Such results could also be explained by the theory that the utility function itself depends on the lottery (Becker \& Sarin, 1987).

In lottery-dependent utility theory, the basic premise of an expectation is prescrved at the expensc of permitting the utility function to change in different lotteries. Allowing the utility function to depend on the lottery seems a natural extension of the theory that "utility" changes to "value" when probabilities become zero or one. By restricting the ways in which utility can change across situations, one can test the theory. Daniels and Keller (1992) compare the predictive accuracy of expected utility theory and lottery-dependent expected utility theory in a choice-based procedure.

Currim and Sarin (1992) also compare the accuracy of lottery-dependent against expected utility and weighted utility theory as well, using several techniques. Currim and Sarin (1992) review other evidence relevant to this assessment and conclude that when the theories are fit to data and the parameters are used to predict to new data, the simpler, expected utility theory is as accurate as the more complex theories, if not more so. As noted by Currim and Sarin, with a different specification and perhaps improved assessment techniques, lottery-dependent theory might perform better.

\section{ELLSBERG'S PARADOX}

Choices between ambiguous events do not conform to subjective expected utility theory (Ellsberg, 1961). For example, suppose there are 100 balls in an urn, which contains 33 red balls and 67 balls that are either blue or green. Suppose one ball will be drawn at random, and payoffs will be made only as follows: Gamble $\mathrm{R}$ pays $\$ 100$ if a red ball is drawn; gamble $G$ pays $\$ 100$ if a green ball is drawn; gamble $R B$ pays $\$ 100$ if either a red or blue ball is drawn; gamble GB pays $\$ 100$ if either a green or blue ball is drawn. Many people prefer gamble $\mathrm{R}$ to $\mathrm{G}$ and $\mathrm{GB}$ to $\mathrm{RB}$, contrary to subjective expected utility theory, which requires that the choice between red and green should be independent of the payoff for blue.

\section{BUYING AND SELLING PRICES}

Buying and selling prices assigned to gambles and goods are farther apart than predicted by utility theory (Knetch \& Sinden, 1984; Harless, 
1989). They also differ in rank order; people will offer to pay more for $N$ than $\mathrm{W}$, but demand more to sell $\mathrm{W}$ than $\mathrm{N}$, where $\mathrm{W}$ is a binary gamble with a wide range of outcomes and $\mathrm{N}$ is a gamble with slightly smaller expected value and a smaller range of outcomes (Birnbaum \& Stegner, 1979; Birnbaum \& Sutton, 1992; Birnbaum, Coffey, Mellers, \& Weiss, 1992). These changes in rank order can be explained by the theory that the configural weight of the lower-valued outcome changes as a function of the judge's point of view (buyer vs seller), but the utility function is unchanged in different viewpoints.

Configural-weight theory was developed to explain violations of independence in judgment cxperiments (Birnbaum, 1974, 1982; Birnbaum \& Stegner, 1979). Rather than attributing attitude toward risk entirely to the utility function, risk aversion or risk seeking can be produced in part by configural weighting (Birnbaum et al., 1992). Configural-weight theory is closely related to rank-dependent utility theories (Chew, Karni, \& Safra, 1987; Lopes, 1990; Luce, 1986, 1991; Luce \& Narens, 1985; Miyamoto, 1989; Quiggin, 1982; Wakker, 1989, in press; Yaari, 1987; see also Machina, 1982), which were developed independently. Rank-dependent utility theories can accommodate violations of independence because the weight of an outcome can depend on its rank among the other outcomes as well as its probability.

\section{VIOLATIONS OF BRANCH INDEPENDENCE}

Branch independence is the assumption that if two gambles have a branch in common (the same outcome at the same probability), then the effect of other outcomes should be independent of the value of that common branch. Birnbaum et al. (1992) found that a .5 probability to win $\$ 80$ or $\$ 8$ was judged higher on the average than a .5 probability to win $\$ 80$, a .4 chance to receive $\$ 16$, and a .1 chance to get $\$ 1$. However, when the common branch was changed from $\$ 80$ to $\$ 0$, the order of judgments reversed. Branch independence is implied by nonconfigural theories, such as Eq. (1), but not by configural-weight theories (Birnbaum \& Stegner, 1979; Birnbaum et al., 1992; Lynch, 1979), which allow the weight of an outcome to depend on the other outcomes in each gamble.

\section{JUDGMENTS OF RISK}

Usually, people prefer gambles that seem lower in risk, but judgments of risk seem to involve something separate from attractiveness. The idea that risk might be a distinct psychological construct that might help us understand preferences for gambles has been explored by Coombs and Lehner (1984), Luce and Weber (1986), Nygren (1977), Weber (1984), and Keller, Sarin, and Weber (1986), among others.

Weber, Anderson, and Birnbaum (1992) compare judgments of risk and 
attractiveness in order to elucidate the relationships between these two kinds of judgments and also to test between configural and nonconfigural theories of risk and attractiveness. A key aspect of their paper is to test whether the effect of a given branch depends on the number, value, and variance of the other outcomes.

\section{VIOLATIONS OF MONOTONICITY}

In judgment tasks, where gambles are judged separately on different trials, prices can violate dominance (monotonicity). People assign a higher average price to the gamble with a .95 probability to win $\$ 96$, otherwise $\$ 0$, than they do to the gamble with the same chance to win $\$ 96$, otherwise \$24, even though the latter gamble dominates the former (Birnbaum et al., 1992; Mellers, Weiss, \& Birnbaum, 1992). When offered a direct choice, however, they rarely choose the dominated gamble (Birnbaum \& Sutton, 1992). Because monotonicity is so compelling, one might be tempted to conclude that if judgments violate this principle and preferences satisfy it, then choice should be the preferred method for assessing human behavior. However, choices can violate transitivity, whereas numerical judgments always satisfy this property.

\section{INTRANSITIVITY OF PREFERENCES}

Preferences are not always transitive. It is possible to select gambles so that some subjects will tend, predictably, to choose A over B, B over C, and C over A (Tversky, 1969). Systematic violations of transitivity would rule out large classes of theories, but they are apparently considered exceptions to the rule. When confronted with evidence of their intransitivity, people seem to consider it an error, as they do violations of monotonicity in judgment. Subsequent theories investigated by Tversky have assumed transitivity (Kahneman \& Tversky, 1979; Tversky \& Kahneman, 1986; Tversky, Sattath, \& Slovic, 1988).

\section{IRREGULARITY OF CHOICE}

Choice proportions show a contextual effect in which the probability of selecting A from the set $[\mathrm{A}, \mathrm{B}, \mathrm{C}]$ can exceed the probability of choosing A from the set [A, B]. Huber, Payne, and Puto (1982) used alternatives, $A$ and $B$, which were nearly indifferent, and then introduced a new alternative, $C$, which was dominated on all dimensions by alternative $A$, but which was intermediate between $\mathrm{A}$ and $\mathrm{B}$ on other dimensions.

\section{METHODS OF ELICITATION AND PREFERENCE REVERSALS}

Gambles appear to have different values when assessed by different methods (Hershey et al., 1982; Hershey \& Schoemaker, 1985; von Win- 
terfeldt \& Edwards, 1986). For example, a subject asked to establish a certainty equivalence for a $50-50$ gamble to receive $\$ 200$ or $\$ 0$ may say that it is worth $\$ 50$. However, when asked later to assign a probability equivalence, $p$, such that $\$ 50$ for sure is indifferent to the gamble to win $\$ 200$ with probability $p$, otherwise $\$ 0$, a consistent subject should say ".5," but typically says, ". $4 . "$

Schoemaker and Hershey (1992) distinguish three possible causes for such inconsistencies. The random noise theory attributes the effect to random error since the typical result can be described as "regression" from the first to the second task. The anchoring interpretation assumes that certainty equivalents are averages of "true" values and anchors presented in the experiment. The reframing hypothesis assumes that the judge recodes the outcomes in the probability equivalence task into deviations from the certainty value, which becomes an "aspiration level," or zero point. Schoemaker and Hershey fit their results as a combination of these factors.

The preference order of gambles also changes in different tasks. A "preference reversal" is said to occur when subjects assign a higher price or judgment to gamble $\mathrm{A}$ than $\mathrm{P}$, but prefer gamble $\mathrm{P}$ to $\mathrm{A}$ in a direct comparison.

In the "classic" preference reversal (Lichtenstein \& Slovic, 1971; Lindman, 1971), the gambles have equal expected value, and gamble $\mathrm{A}$ has a smaller probability to win a larger amount, whereas gamble $\mathbf{P}$ has a higher probability to win a smaller amount. Ratings of the attractiveness of gambles and the prices assigned to them also reverse rank order. People will often rate $\mathrm{P}$ higher than $\mathrm{A}$, but will assign a higher price to $\mathrm{A}$ than to $P$. Preference reversals have received considerable attention in recent investigations (e.g., Bostic, Herrnstein, \& Luce, 1990; Goldstein \& Einhorn, 1987; Grether \& Plott, 1979; Karni \& Safra, 1987; Slovic \& Lichtenstein, 1983; Tversky et al., 1988).

Goldstein and Busemeyer (1992) explore a lexicographic criterion model as an explanation of changes in rank order produced by experimental conditons. This model generalizes the lexicographic semiorder used by Tversky to account for intransitive preferences. Different experimental conditions are theorized to affect internal response processes (as opposed to evaluation of the stimuli). Techniques for testing the model are illustrated in an application to data.

Busemeyer and Goldstein (1992) also address the problem of preference reversals, from the viewpoint of decision field theory. In that theory, preferences are the result of an aggregation of considerations favoring one alternative or the other in a dynamic, stochastic process. The theory allows predictions of decision times as well as choice proportions, and the 
theory is applied to pricing judgments as well. A key concept is the variance of subjective comparisons, an idea that is also useful for understanding violations of scalability (Busemeyer, 1985).

Mellers, Ordóñez, \& Birnbaum (1992) test three theories of preference reversals between ratings and prices. Contingent weighting theory (Tversky et al., 1988) assumes that the process of combining probability and outcomes is invariant, but the weights of these factors change in different tasks. Expression theory (Goldstein \& Einhorn, 1987) assumes that an implicit judgment process is affected by the within-gamble context. Change of process theory (Mellers et al., 1992) assumes that the scales of probability and utility are invariant, but different tasks and contexts induce the judge to utilize different processes for combining the scales.

\section{CONTEXTUAL EFFECTS}

In judgment research, it is well known that the judgment of a given stimulus depends on the other stimuli presented; however, contextual effects have received less attention in decision making (Parducci, 1968). Mellers et al. (1992) investigate whether utility functions and/or the judgment processes depend on the distribution of other gambles offered for judgment. Mellers et al. (1992) find that when most of the other gambles are lower in expected value, a gamble will be judged higher than when it is presented with gambles of higher expected value (see also Mellers \& Birnbaum, 1983). Stevenson (1992) manipulates the range of time durations to investigate whether the effect of a given delay depends on the other delays presented in the study.

Mellers et al. (1992) also report that the rank order of judgments can be altered by the choice of other gambles presented. In one context, gamble $A$ is judged higher than gamble $P$; however, when new gambles (with zero and near-zero values of probability and amount) are also presented for judgment, gamble $\mathrm{P}$ is judged higher than gamble $\mathrm{A}$. This contextual experiment was suggested by the change of process theory.

\section{UNIFYING THEMES AND THEORETICAL DIFFERENCES}

The papers in this issue all deal with problems that arise in applying nonconfigural theories [e.g., Eq. (1)] to human judgments, but the authors approach these exceptions from different theoretical perspectives. One important difference concerns the nature of utility. Stevenson (1992), Currim and Sarin (1992), and Daniels and Keller (1992) reason that utility may change as the risk of the situation changes; however, Weber $e t$ al. (1992) and Mellers et al. (1992) retain the concept of an invariant utility function. The papers also differ in the invariances (besides utility) they try to preserve: linearity in probability, weights, aggregation process, or response process. Because the papers in this issue treat different phenom- 
ena, these alternate theoretical stances do not always stand in direct contradiction.

Like the blind philosophers who felt different parts of an elephant and argued over its true nature ["It is like a wall." (side) "It is like a snake." (trunk) "It is like a tree." (leg) "It is like a rope." (tail)], the authors in this issue present different perspectives on utility. The reader is invited to study these views to decide whether utility is like that deity the ancient Celts were loathe to name (who changes shape whenever observed), or whether it is really like a single, invariant elephant that is merely too large to grasp in one examination.

\section{REFERENCES}

Allais, M. (1979). The foundations of a positive theory of choice involving risk and a criticism of the postulates and axioms of the American School. In M. Allais \& O. Hagen (Eds.), Expected utility hypothesis and the Allais paradox. Dordrecht: Reidel.

Becker, J., \& Sarin, R. K. (1987). Lottery dependent utility. Management Science, 33, $1367-1382$.

Bell, D. E., \& Raiffa, H. (1988). Marginal value and intrinsic risk aversion. In D. Bell, H. Raiffa, \& A. Tversky (Eds.), Decision making: Descriptive, normative, \& prescriptive interactions. New York: Wiley.

Birnbaum, M. H. (1974). The nonadditivity of personality impressions. Journal of Experimental Psychology (Monograph), 102, 543-561.

Birnbaum, M. H. (1982). Controversies in psychological measurement. In B. Wegener (Ed.), Social attitudes and psychophysical measurement. (pp. 401-485). Hillsdale, NJ: Erlbaum.

Birnbaum, M. H. Coffey, G., Mellers, B. A., \& Weiss, R. (1992). Utility measurement: Configural-weight theory and the judge's point of view. Journal of Experimental Psychology: Human Perception and Performance, 18, 331-346.

Birnbaum, M. H. \& Stegner, S. E. (1979). Source credibility in social judgment: Bias, expertise, and the judge's point of view. Journal of Personality and Social Psychology, 37, 48-74.

Birnbaum, M. H., \& Sutton, S. (1992). Scale convergence and utility measurement. Organizational Behavior and Human Decision Processes, 52, 183-215.

Rostic, R., Herrnstein, R. J., \& Luce, R. D. (1990). The effect on the preference-reversal phenomenon of using choice indifference. Journal of Economic Behavior and Organization, 13, 193-212.

Busemeyer, J. R. (1985). Decision making under uncertainty: Simple scalability, fixed sample, and sequential sampling models. Journal of Experimental Psychology: Learning, Memory, and Cognition, 11, 583-564.

Busemeyer, J. R., \& Goldstein, W. M. (1992). Linking together different measures of preference: $\Lambda$ dynamic model of matching derived from decision field theory. Organizational Behavior and Human Decision Processes, 52, 370-396.

Chew, S. H., Karni, E., \& Safra, Z. (1987). Risk aversion in the theory of expected utility with rank dependent probabilities. Journal of Economic Theory, 42, 370-381.

Coombs, C. H., \& Lehner, P. E. (1984). Conjoint design and analysis of the bilinear model: An application to judgments of risk. Journal of Mathematical Psychology, 38, 1-42.

Currim, I. S., \& Sarin, R. K. (1992). Robustness of expected utility model in predicting individual choices. Organizational Behavior and Human Decision Processes, 52, 544 568 . 
Daniels, R. L., \& Keller, L. R. (1992). Choice-based assessment of utility functions. Organizational Behavior and Human Decision Processes, 52, 524-543.

Edwards, W. (1954). The theory of decision making. Psychological Bulletin, 51, 380-417.

Ellsberg, D. (1961). Risk, ambiguity and the Savage axioms. Quarterly Journal of Economics, 75, 643-649.

Ferguson, C. E. (1966). Microeconamic theory. Homewood, IL: Richard D. Irwin, Inc.

Fishburn, P. C. (1983). Research in decision theory: A personal perspective. Mathematical Social Sciences, 5, 129-148.

Goldstein, W. M., \& Busemeyer, J. R. (1992). The effect of "irrelevant" variables on decision making: Criterion shifts in preferential order. Organizational Behavior and Human Decision Processes, 52, 425-454.

Goldstein, W., \& Einhorn, H. J. (1987). A theory of preference reversals. Psychological Review, 94, 236-242.

Grether, D. M., \& Plott, C. R. (1979). Economic theory of choice and the preference reversal phenomenon. American Economic Review, 623-638.

Harless, D. W. (1989). More laboratory evidence on the disparity between willingness to pay and compensation demanded. Journal of Economic Behavior and Organization, 11, 359-379.

Hershey, J. C., Kunreuther, H. C., \& Schoemaker, P. J. (1982). Sources of bias in assessment procedures for utility functions. Management Science, 28, 926-954.

Hershey, J. R., \& Schoemaker, P. J. (1985). Probability vs certainty equivalence methods in utility measurement: Are they equivalent? Management Science, 31, 1213-1231.

Huber, J., Payne, J. W., \& Puto, C. (1982). Adding asymmetrically dominated alternatives: Violations of regularity and the similarity hypothesis. Journal of Consumer Research, 9, 90-98.

Kahneman, D., \& Tversky, A. (1979). Prospect theory: An analysis of decision under risk. Econometrica, 47, 263-291.

Karni, E., \& Safra, Z. (1987). "Preference reversal" and the observability of preferences by experimental methods. Econometrica, 55, 675-685.

Keeney, R., \& Raiffa, H. (1976). Decisions with multiple objectives: Preferences and value tradeoffs. New York: Wiley.

Keller, L. R., Sarin, R. K., \& Weber, M. (1986). Empirical investigation of some properties of the perceived riskiness of gambles. Organizational Behavior and Human Decision Processes, 38, 114-130.

Knetsch, J. L., \& Sinden, J. A. (1984). Willingness to pay and compensation demanded: Experimental evidence of an unexpected disparity in medsures of value. The Quarterly Journal of Economics, 99, 507-521.

Krantz, D. H., Luce, R. D., Suppes, P., \& Tversky, A. (1971). Foundations of measurement (Vol. 1). New York: Academic Press.

Lichtenstein, S., \& Slovic, P. (1971). Reversals of preference between bids and choices in gambling decisions. Journal of Experimental Psychology, 89, 46-55.

Lindman, H. R. (1971). Inconsistent preferences among gambles. Journal of Experimental Psychology, 89, 390-397.

Lopes, L. (1990). Re-modeling risk aversion: A comparison of Bernoullian and rank dependent value approaches. In G. M. von Furstenberg (Ed.) Acting under uncertainty. Boston: Kluwer Academic Publishers.

Luce, R. D. (1986). Comments on Plott and on Kahneman, Knetsch, and Thaler. Journal of Business, 59, S337-S343.

Luce, R. D. (1991). Rank- and sign-dependent linear utility models for binary gambles. Journal of Economic Theory, 53, 75-100. 
Luce, R. D., \& Narens, L. (1985). Classification of concatenation measurement structures according to scale type. Journal of Mathematical Psychology, 29, 1-72.

Luce, R. D., \& Weber, E. U. (1986). An axiomatic theory of conjoint, expected risk. Journal of Mathematical Psychology, 30, 188-205.

Lynch, J. G. (1979). Why additive utility models fail as descriptions of choice behavior. Journal of Experimental Social Psychology, 15, 397-417.

Machina, M. J. (1982). Expected utility analysis without the independence axiom. Econometrica, 50, 277-323.

Mellers, B. A., \& Birnbaum, M. H. (1983). Contextual effects in social judgment. Journal of Experimental Social Psychology, 19, 157-171.

Mellers, B. A., Ordóñez, L., \& Birnbaum, M. H. (1992). A change of process theory for contextual effects and preference reversals in risky decision making. Organizational Behavior and Human Decision Processes, 52, 331-369.

Mellers, B. A., Weiss, R., \& Birnbaum, M. H. (1992). Violations of dominance in pricing judgments, Journal of Risk and Uncertainty, 5, 73-90.

Miyamoto, J. M. (1989). Generic utility theory: Measurement foundations and applications in multiattribute utility theory. Journal of Mathematical Psychology, 32, 357-404.

Nygren, T. E. (1977). The relationship between perceived risk and attractiveness of gambles: A multidimensional analysis. Applied Psychological Measurement, 1, 565-579.

Parducci, A. (1968). The relativism of absolute judgment. Scientific American, 219, 84-90.

Payne, J. W. (1973). Approaches to decision making under risk: Moments versus risk dimensions. Psychological Bulletin, 80, 439-463.

Quiggin, J. (1982). A theory of anticipated utility. Journal of Economic Behavior and Organization, 3, 324-345.

Raiffa, H. (1968). Decision analysis. Reading, MA: Addison-Wesley.

Savage, L. J. (1954). The foundations of statistics. New York: Wiley.

Schoemaker, P. J. (1982). The expected utility model: Its variants, purposes, evidence and limitations. Journal of Economic Literature, 20, 529-563.

Schoemaker, P. J., \& Hershey, J. C. (1992). Utility measurement: Signal, noise, and bias. Organizational Behavior and Human Decision Processes, 52, 397-424.

Shanteau, J. (1974). Component processes in risky decision making. Journal of Experimental Psychology, 103, 680-691.

Shanteau, J., \& Troutman, C. M. (1992). A psychophysical evaluation of diminishing returns in riskless decision making. Organizational Behavior and Human Decision Processes, 52, 569-579.

Slovic, P., \& Lichtenstein, S. (1983). Preference reversals: A broader perspective. American Economic Review, 596-605.

Slovic, P., Lichtenstein, S., \& Fischhoff, B. (1988). Decision making: In R. C. Atkinson, R. J. Herrnstein, G. Lindzey, \& R. D. Luce (Eds.), Stevens' Handbook of Experimental Psychology (Vol. 2). New York: Wiley.

Stevens, S. S. (1975). Psychophysics. New York: Wiley.

Stevenson, M. K. (1986). A discounting model for decisions with delayed positive or negative outcomes. Journal of Experimental Psychology: General, 115, 131-154.

Stevenson, M. K. (1992). The impact of temporal context and risk in the judged value of future outcomes. Organizational Behavior and Human Decision Processes, 52, 455491.

Thurstone, L. L. (1931). The indifference function. Journal of Social Psychology, 2, 139167.

Tversky, A. (1967). Additive, utility and subjective probability. Journal of Mathematical Psychology, 4, 175-201.

Tversky, A. (1969). Intransitivity of preferences. Psychological Review, 76, 31-48. 
Tversky, A., \& Kahneman, D. (1986). Rational choice and the framing of decisions. Journal of Business, 59, S251-S278.

Tversky, A., Sattath, S., \& Slovic, P. (1988). Contingent weighting in judgment and choice. Psychological Review, 95, 371-384.

von Neumann, J., \& Morgenstern, O. (1947). Theory of games and economic behavior. Princeton, NJ: Princeton University Press.

von Winterfeldt, D., \& Edwards, W. (1986). Decision analysis and behavioral research. Cambridge: Cambridge University Press.

Wakker, P. (1989). Transforming probabilities without violating stochastic dominance. In E. E. Roskam (Ed.), Mathematical psychology in progress. Berlin/New York: Springer-Verlag.

Wakker, P. (in press). Additive representations on rank-ordered sets. II. The topological approach. Journal of Mathematical Economics.

Weber, E. U. (1984). Combine and conquer: A joint application of conjoint and functional approaches to the problem of risk measurement. Journal of Experimental Psychology: Human Perception and Performance, 10, 179-194.

Weber, E. U., Anderson, C. J., \& Birnbaum, M. H. (1992). A theory of perceived risk and attractiveness. Organizational Behavior and Human Decision Processes, 52, 492-523. Yaari, M. E. (1987). The dual theory of choice under risk. Econometrica, 55, 95-115.

RECEIVED August 6, 1991 